\title{
Minimizing the Quality Costs on Printed Circuit Board -3D-SJI Will Change Communications among Human/machine Resources
}

\author{
Toshiyuki SUGIYAMA* \\ プリント実装基板における「品質コストの最小化」-3D-SJI で \\ 資源（人財／機械）間コミュニケーションが変化する
}

杉山 俊幸*

* OMRON Corporation (Shiokoji Horikawa, Shimogyo-ku, Kyoto 600-8530)

*オムロン株式会社（７ 600-8530 京都市下京区塩小路堀川東入）

\section{Introduction}

The Business environment surrounding Electronic packaging is changing rapidly. Since the reliability in product and the reduction in cost are required at the same time, we must grasp the trends in global standards. The global standards discussed here include: quality management systems such as ISO9001 and ISO/TS16949; manufacturing trends such as IoT and Industrie4.0; and IPC standards in reliability. In this paper, we will discuss the challenges that we face in the Electronic packaging industry. Further, we will describe the quality management/control and its testing/inspection techniques to Diagnose, to Define, and to Detect and how they are applied to the industry. Finally, we will explain how an organization can address the issues using the techniques.

\section{Trends and Issues on Electronic Packaging}

2.1 Quality management issue (To Diagnose)

With the increased public awareness toward safety and environmental protection, the quality management systems were implemented in order to cope with challenges that had come across over time. Figure 1 shows the domestic standards from around the globe that have become the international standards.

According to the ISO survey, more than one million organizations worldwide have reached the ISO 9001 certification. The revised version issued in September 2015 (ISO9001: 2015) stated the word "risk" multiple times in order to catch peoples' attention throughout the document. Clearly the prevention of potential risks has become of a great importance and any organization must consider them carefully before starting to operate PDCA cycle. And in automotive industry, more than fifty thousand organizations have reached ISO/TS16949 certification. This certification requires the management to address effectiveness (toward customers) and efficiency (toward organization). We must closely watch the next ISO/TS16949 edition on how recent quality related incidents observed in the market will be reflected in the quality management standards.

We tend to focus only on the "failure cost" at management

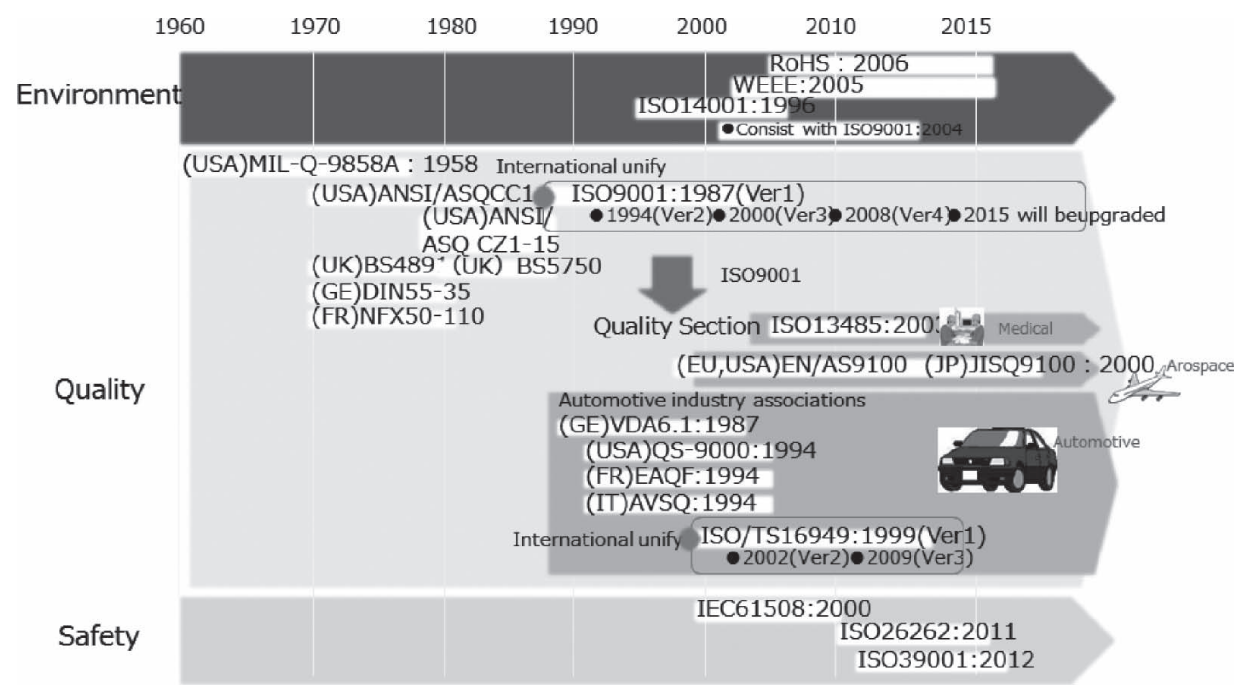

Fig. 1 Current international standards of environment, safety, quality, etc. 


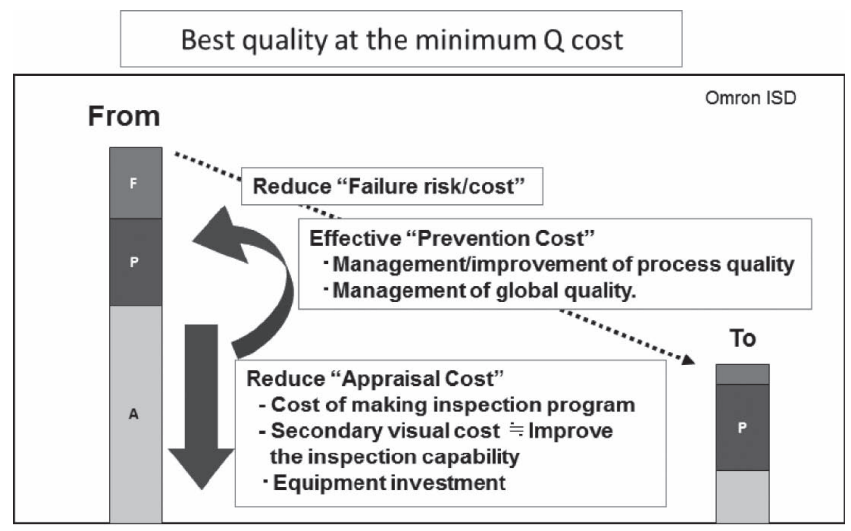

※: Prevention, A: Appraisal, F: Failure

\section{Fig. 2 Best quality at the minimum $Q$ cost}

review process which is known to be one of the most important processes in quality management system. Return on investment is calculated by quality cost management. The strategic management of the costs (i.e. appraisal costs or detection costs) can result in a proper way to measure investment costs on quality. The biggest challenge of quality management is achieving best quality at the minimum quality cost. Setting the higher goal each time and achieving them constantly can not only reduce failure costs but also contribute to enhancing brand recognition and customer loyalty. The ideal state is to minimize the quality costs, which are calculated as the sum of the failure costs and investments like the appraisal costs and detection costs. The challenge is to manage KPI's which indicate ROI (Return On Investment) to the new advanced technologies (equipment, material, method and etc.). ${ }^{1) 3)}$

\subsection{Quality control issue (To Define)}

In this section, I will elaborate on envisioning quality control issue.

In the 1950 s, the Japanese companies began incorporating the statistical quality control and quality circle of quality control process in the United States. Dramatic improvements were brought about to the Japanese manufacturing industries by the enhancements of manufacturing processes. The statistical controls made them possible to actually measure and quantify the quality. Statistical quality control need to use quantification data. Another method of quality control is to form quality circles which are the group activities. Self-initiating groups are organized and solve problems. It is important to have peoples' network within a circle. When a problem solving activity requires an investment in the equipment, a quality circle needs to be formed by workers across related departments. For example, workers in a manufacturing department know the root cause of a serious problem in the product and they lead to solve it by involving design department. To guide the activities to success, the mechanism must be created so that the voluntary and autonomous movements can happen with smooth communications among people concerned in a product manufacturing. In recent years, almost all the major factories have been automated, especially given the revolutionary movement known as Industrie4.0. Today's tasks done by humans will continue to be automated and computerized. The key to inter-resource communications including Human to Human, Human to Machine, and Machine to Machine (i.e. H2H, H2M and M2M, respectively) is the utilization of the mutually understandable languages and quantification (measurement).

The issues remain in the use of conventional inspection system equipment in Electronic Packaging. The language generated by the image processing machine called AOI is not human understandable. Numeric values such as pixel values, brightness level, chromaticity, and peak values generated by the image processing machine are not compatible with other equipment, either. To successfully achieve standardization, the information needs to be refined and provided not only to the limited number of engineers specialized in the particular field but also to all parties involved, while at the same time, communication standards among equipment need to be addressed and standardized.

\subsection{Quality Inspection issue (To Detect)}

In addition to quality control, Inspection plays a big part in quality assurance. "Inspection" refers to the activity to determine if manufactured goods are acceptable or unacceptable. As a result of testing and in comparison with the quality criteria, Inspections are conducted based on the quality judgment criteria (quality acceptance criteria)

The quality criteria related to Electronic Packaging in the United States are as follows: IPC-A-610, J-STD-001, whereas, the international standard is IEC61191. The important objective in Electronic Packaging is the electrical reliability in long-term use (several years to tens of years). In other words, the reliability depends upon the solder joint quality with description associated with it. Post-reflow test, which is the final quality check before shipping the products, has been promoted in the international (or industry) standardization. Once the product is shipped and a defect is detected, the corresponding cost will be enormous. To prevent defects going out in the market, it is the global consensus to put the greatest effort on the standardization in the final test phase. Nowadays, hidden solder joint devices such as bottom electrode components (i.e. BGA and POP) have been increasing. The issue here is that the detecting defects in solder joints are not an easy task because usually the test performed at which printing and mounting phase passes, but later unacceptable parts are caught at the reflow oven phase. The requirements for the test equipment are to meet thorough inspection of devices both visible and invisible from the exterior. 


\section{3Dimension Sensing Technology for Solder Joint Inspection}

Before explaining the technology to solve the above issues, I would like to remind the reader that the requirements are defined in the quality judgement criteria determined by IPC-A-610 and IEC61191 (†JIS-C-61191). The requirement in the IPC-A-610 and IEC61191 standards describes, for example, the amount of component overhang is based on the connected land and the wettability of solder is also based from the land edge to the component electrode. These are very legitimate considering the fact that electronic reliability is essential for the Electronic Packaging. Based on these standards, requirements for sensing technology fall into (1) Land position (2) Electrode posture (3)
Solder shape, as shown in Figure 3.

Please refer to below description about each sensing technology.

\subsection{Extraction technology of land position}

The number of defects caused by solder printing position misalignment can be reduced by correctly placing pads on the chip mounter at the time of solder printing. This is a good example to show that the mechanical precision is not the only composition for the successful operation in Electronic Packaging. At the reflow oven phase, the misalignment becomes even worse because of the difference in each component's coefficient of thermal expansion. Defects may be shipped if operations continue without correcting the land position and only performing $\theta$ correction of the substrate. That is a potential risk in the products

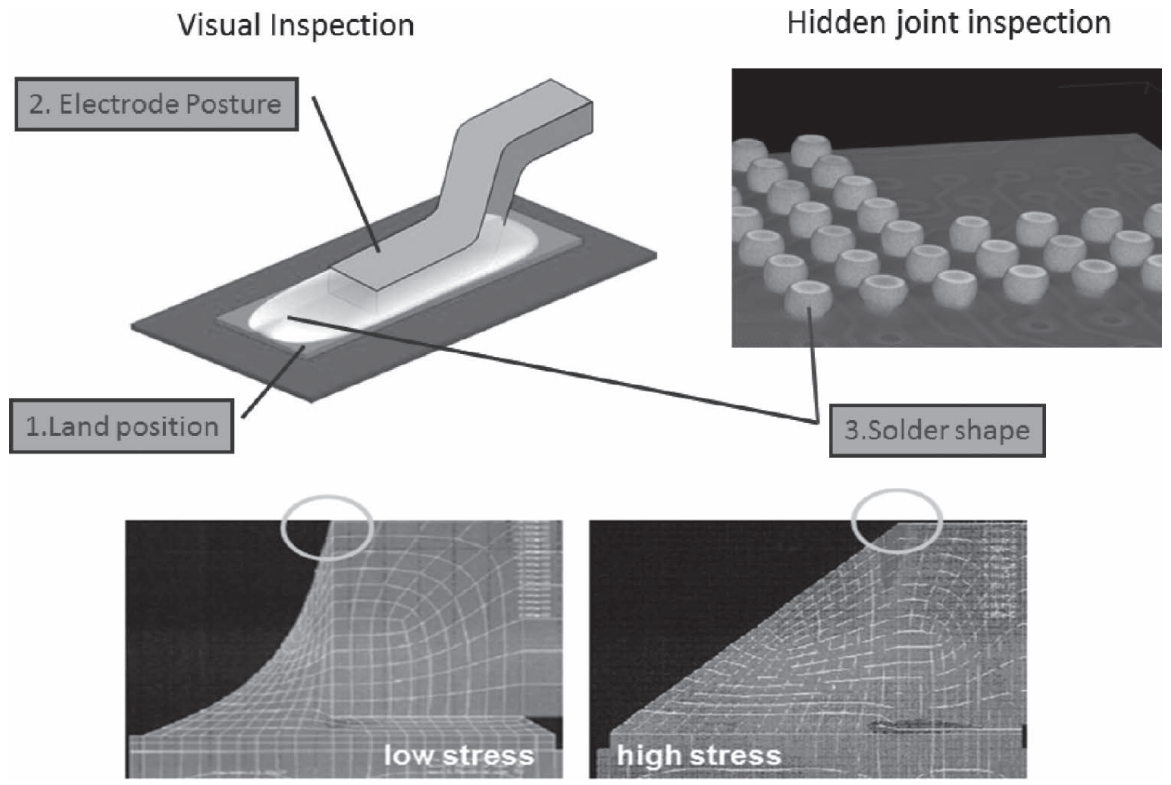

Fig. 3 Solder joint inspection requirements

Detect appropriate land size automatically in the case of making a program.

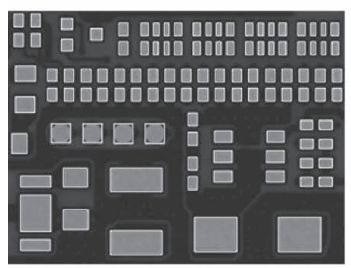

Detect appropriate land position each FOV in the case of inspection mode

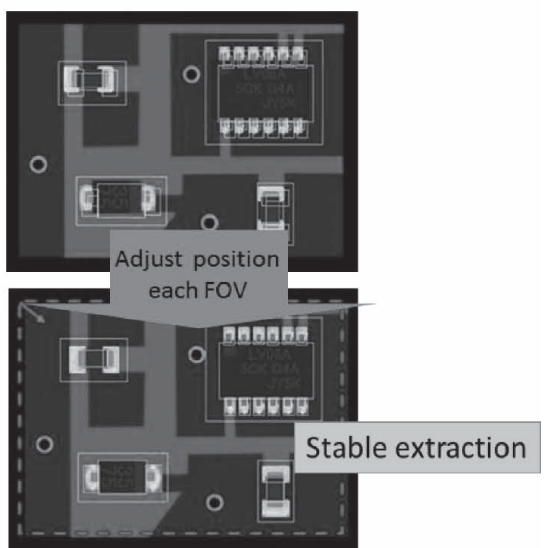

Fig. 4 Land position detection mechanism 
reliability. The placement correction is a well-established technology that has been used for over twenty years. Recently, the accuracy of alignment has improved using the collective and simultaneous correction technique for multiple circuits.

\subsection{Technology of obtaining electrode posture}

The light reflection in test equipment is a big problem for inspection accuracy.

The light reflections are characterized into diffuse or specular (mirror-like) type reflections. Phase shift technique, which uses both the camera and the DLP projector, can measure height of a device with diffusing surfaces. Stereo Method, which uses two camera, can measure height of a device with mirror surfaces. The height can be calculated by comparing two different points of the target objects.

\subsection{Technology of obtaining solder shape}

As described above, when the land and component electrode is electrically connected, checking the physical joint is essential to ensure reliability. By checking wettability, solder shape can be acquired. The color highlight technology once was the de facto standard in the industry and now it is the $3 \mathrm{D}$ reconstruction technology used to satisfy soldering inspection

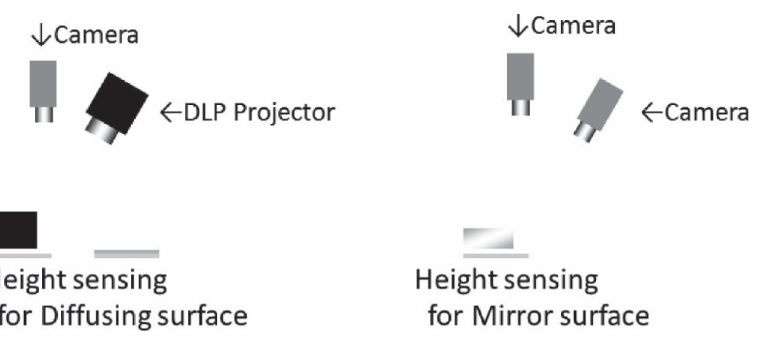

Fig. 5 Obtaining electrode posture with high connection reliability. The color highlight 3D shape reconstruction enables acquiring of information for the specular surface as well as the free-form surface.

In the Solder Joint Inspection (SJI) technology, there are two inspection methods. One is visual inspection and the other is $\mathrm{X}$-ray inspection. Both of them are required to accurately verify solder shape. As for the visual inspection, processing speed is fast and maintenance cost is low. Therefore, inspection facilities are designed to have visual inspection equipment to check most solder joint parts and X-ray inspection equipment to test other hidden solder joint parts like bottom surface electrodes (BGA). The actual X-ray inspection method is 3D-Computed Tomography. Inspection can be achieved without interference from the opposite side of the board because the system is not the same as the traditional transparent method scanned from the top. With the improved processing speeds in recent years, inline inspection has become available for products like automotive circuit board since few numbers of electrode parts are loaded on bottom surface.

Recently, X-ray inspection of solder filling within the throughhole has been attracted to check the connection strength of inserted lead connector.

The connections used to be bound using spot flow (selective soldering) or hand soldering methods. Nowadays, the new process of printing a paste within the through-hole and then inserting lead connector become general process. This method eliminates some processes so that the cost per solder joint can be dramatically reduced. However there are some risks on the quality assurance. This is one of the new trends that show more importance in the X-ray inspection. ${ }^{4}$

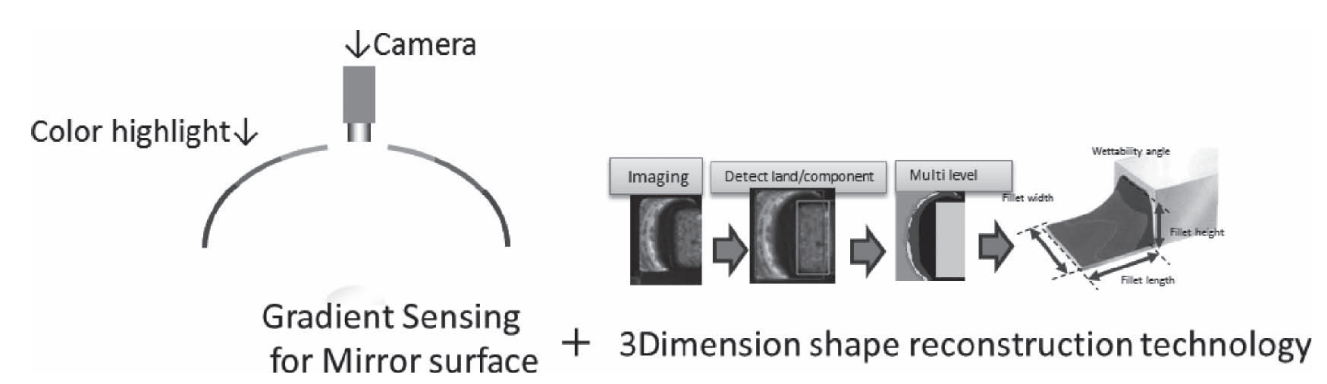

Fig. 6 Obtaining solder shape
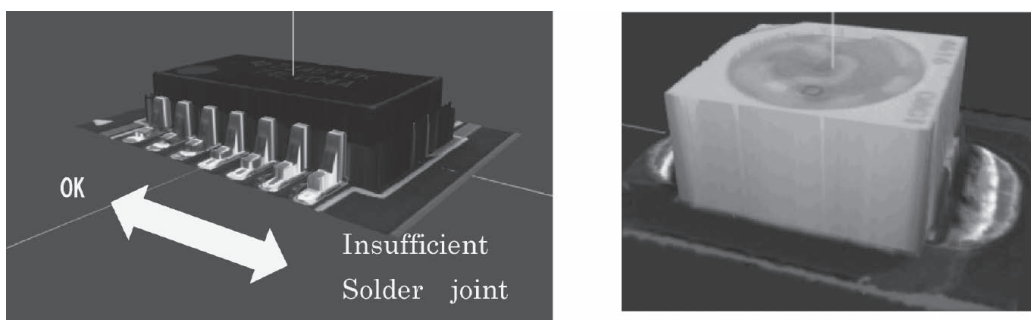

Fig. 7 3Dimension Solder Joint Inspection image 

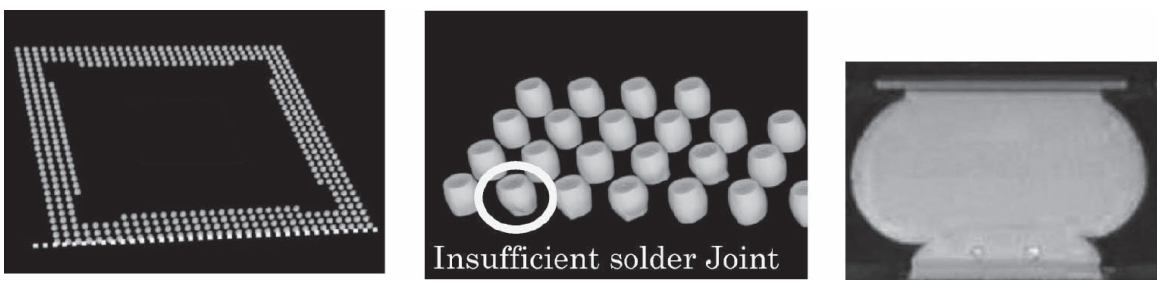

Fig. 8 BGA head in pillow sectional view and 3D-SJ X-ray image

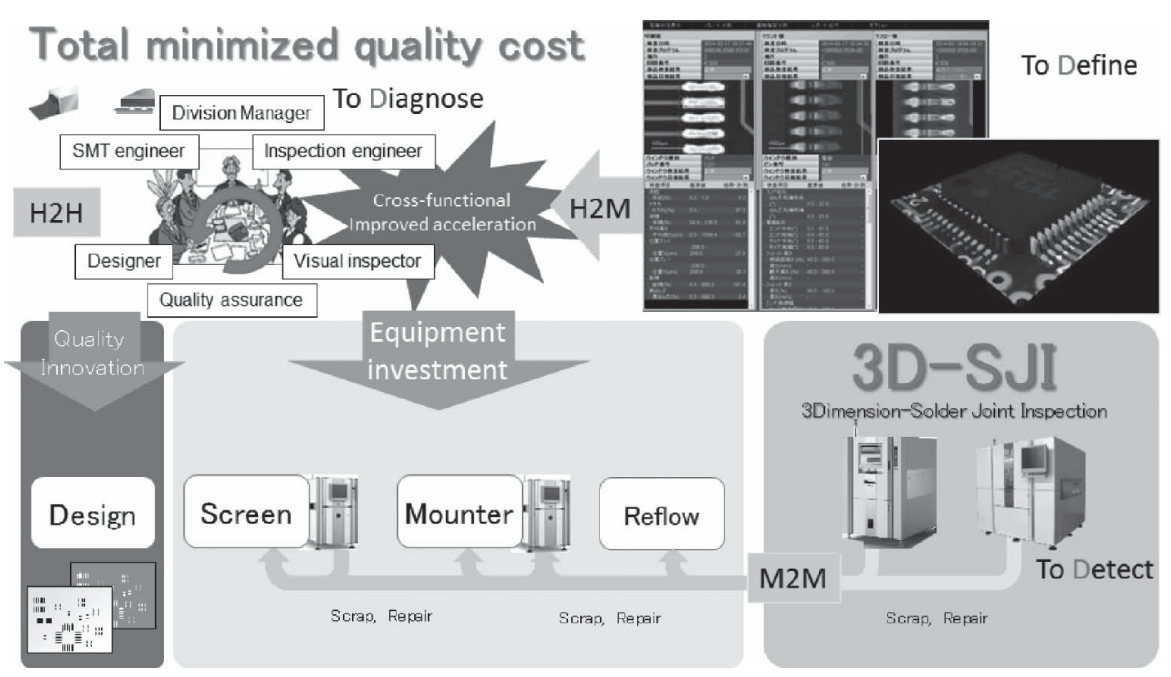

Fig. 9 Inter-resource communications

\section{Conclusion}

3D sensing technology brings a company big advantage to its quality management control by supporting high quality product delivery. The technology makes it possible to quantify data generated in the process of electronic packaging. It also accelerates peoples' communication. The communication between inspection and surface mounting engineers performing different tasks used to be very difficult. Inspection operators specialize in defect detection, while surface mounting operators focus on creating non-defect products. However, many engineers are utilizing automated solutions. For example, surface mount engineers have begun to use inspection equipment to verify product. This kind of movement can lead to multi-skilled engineers and implementation of job rotation program. We believe that it will contribute to the autonomous and continuous quality improvement within the organization.

Furthermore, if we can successfully replace the manual operations with automatic quality improvement, accurate data exchanges will be achieved and it will result in high effectiveness and performance. When it becomes a reality, total costs which include the inspection and the prevention costs as well as the failure costs can constantly be reduced.

(2016.3.10- 受理)

\section{References}

1) T. Hiromoto and F. Hiki: "Cost Accounting, Theory and Practice 3th Edition," CHUOKEIZAI-SHA HOLDINGS, 2015

2) J. M. Juran: "Quality Control Handbook 5th Edition," McGrawHill, 1988

3) D. H. Stamatis: "Quality Assurance," CRC Press, 2015

4) JEITA: “2015 Japan Jisso Technology Road-map,” JEITA, pp. $334-370,2015$

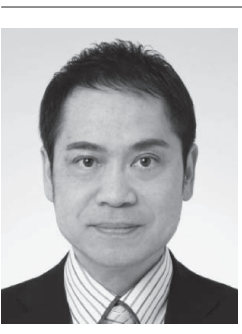

杉山俊幸（すぎやま としゆき） 著者紹介 IntPE (Jp)/APEC Engineer (Industrial) P.E.Jp (Industrial)/PWB Comsultant. IPEJ (Institution of Professional Engineers, Japan) member

IPEA 国際エンジニア/APECエンジニア (Industrial) /技術士（経営工学) / PWB コンサル タント。

日本技術士会会員。グローバル実装の 3 現知見を ベースに検查設備や品質システムを企画開発。現 在はコンサルティング業務に従事。 